\title{
Estudo da variação da concentração sérica de fenobarbital em cães cronicamente medicados
}

Helena Arantes do

AMARAL ${ }^{1}$

Maria Helena Matiko Akao

LARSSON $^{1}$

Correspondência para:

HELENA ARANTES DO AMARAL

Departamento de Clínica Médica

Faculdade de Medicina Veterinária e

Zootecnia

Universidade de São Paulo

Av. Prof. Dr. Orlando Marques de Paiva,

87-Cidade Universitária

05508-000 São Paulo-SP

harantes@usp.br

Recebido para publicação: 12/05/2004 Aprovado para publicação: 21/09/2005

1 - Departamento de Clínica Médica da Faculdade de Medicina Veterinária

e Zootecnia da Universidade de São Paulo, São Paulo - SP

\section{Resumo}

Com a finalidade de avaliar a variação na concentração sérica do fenobarbital durante um intervalo de 12 horas da sua administração, as concentrações séricas foram mensuradas a cada duas horas em 30 cães cronicamente medicados, durante no mínimo um mês. A determinação dos valores séricos de fenobarbital, por meio de Imunofluorescência polarizada. Os valores de meia-vida obtidos variaram de 13-131 horas, sendo que a maioria dos cães atingiram o estado de equilíbrio dinâmico por volta de 15 dias, e todos após quatro semanas, recomendando-se assim monitoração após quatro semanas do início da terapia ou após cada ajuste de dose. Houve diferença significante entre as médias das amostras coletadas duas e quatro horas (pico) com as das amostras coletadas imediatamente antes e oito, 10 e 12 horas após sua administração. Assim, para a monitoração, pode-se realizar a coleta sangüínea, imediatamente antes da administração do fenobarbital, ou em qualquer horário, entre oito a 12 horas após sua administração e nos casos suspeitos de intoxicação uma segunda amostra pode ser coletada dentro de duas a quatro horas após a sua administração.

\section{Introdução}

O fenobarbital $\left(\right.$ Gardenal $\left.^{\circledR}\right)$ foi introduzido por Hauptmann, em 1912, para o tratamento de epilepsia humana, sendo o medicamento mais utilizado na manutenção de cães epilépticos, devido à sua eficácia, baixo custo e mínima toxicidade. ${ }^{1,2,3}$. Por ser um auto-indutor de enzimas microssomais hepáticas do sistema P- 450, aumenta a sua própria metabolização e a biotransformação de outras drogas administradas concomitantemente, sendo hepatotoxicidade um dos efeitos colaterais mais severos em animais cronicamente medicados ${ }^{4,5}$.

Existe uma considerável variação na farmacocinética dos anticonvulsivantes entre indivíduos da mesma espécie e uma ampla variação na concentração sérica para a mesma dosagem oral ${ }^{2}$, sendo que a concentração sérica se correlaciona muito melhor com os efeitos terapêutico e tóxico do que com a dose oral ${ }^{1,2,4}$. O objetivo da monitoração é manipular a dose da droga usando concentrações séricas como guia, para otimizar a eficácia e evitar toxicidade ${ }^{5}$.

Devido à grande importância da monitoração para otimização da terapia, alguns cuidados devem ser tomados. A amostra sangüínea só deve ser coletada após ter-se atingido o estado de equilíbrio dinâmico, o qual é atingido, segundo estudos realizados em cães, após cinco meiasvidas $^{6,4,7,5}$. O estado de equilíbrio dinâmico refere-se à concentração estável da droga em um taxa constante de eliminação ${ }^{7}$. Meia-vida é um conceito cronológico e se refere ao tempo que determinada concentração da droga leva para reduzir-se à sua metade; quanto mais curta a meia-vida, maior variação de concentração plasmática entre as doses $^{8,9}$. Outros aspectos importantes que se deve levar em consideração, ao realizar a monitoração sérica, é a escolha do momento da colheita da amostra sangüínea em relação ao horário da administração da droga e o 
número necessário de amostras. Recomendações atuais para a monitoração de cães epilépticos propõem que o horário mais indicado é 11 horas após a administração (valor mais baixo), se o objetivo for ajuste da dose e que uma nova colheita, no horário de pico (concentração plasmática máxima), deva ser acrescentada quando da suspeita de intoxicação $0^{6,4,7,3}$. Não existe um consenso quanto ao horário de pico, sendo que alguns autores acreditam que o pico seja atingido em duas a quatro horas ${ }^{4,10}$, enquanto outros, em quatro a seis horas ${ }^{7}$ ou em quatro a oito horas ${ }^{11,12}$. Já Levitski e Trepanier ${ }^{13}$ não observaram variação significante nas médias das concentrações séricas, sugerindo que uma única amostra, coletada em qualquer horário seria suficiente para a monitoração.

O fenobarbital, por induzir sua auto metabolização com o tempo e/ou doses elevadas, poderia diminuir a sua meia- vida de eliminação no tratamento crônico de cães epilépticos. Assim, o presente estudo visou comparar e quantificar as concentrações séricas nos diferentes horários entre as dosagens, em cães cronicamente medicados, com o objetivo de melhor avaliar possíveis flutuações diárias, tempo de meia-vida e suas implicações na otimização da monitoração terapêutica.

\section{Materiais e Métodos}

Foram selecionados cães de várias raças, bem como sem definição racial, com peso variando de $13 \mathrm{~kg}$ a $75 \mathrm{~kg}$, com idade mínima de um ano e máxima de nove anos, sendo oito fêmeas (cinco não castradas e três castradas) e 22 machos. No período de $09 /$ $02 / 2001$ a 23/05/2002 foram colhidas amostras de sangue para a dosagem sérica de fenobarbital de 30 cães em atendimento no Serviço de Clínica Médica do Hospital Veterinário da Universidade de São Paulo (HOVET-USP) com histórico de convulsões generalizadas recorrentes, medicados com a mesma dose de fenobarbital, a cada 12 horas, há pelo menos 30 dias. Os cães foram mantidos no HOVET, isolados numa sala, antes do horário de administração matutina do fenobarbital. Nenhum outro medicamento, além do fenobarbital, estava sendo utilizado, simultaneamente, exceto o brometo de potássio, em 10 animais. Para cada cão foi realizada a colheita de sangue imediatamente antes da administração matutina do fenobarbital e a cada duas horas, no total de sete colheitas por animal, sendo a última amostra coletada imediatamente antes do fornecimento da dose noturna do medicamento. As amostras de sangue foram obtidas das veias cefálica, femoral ou jugular, colocadas em tubos estéreis e centrifugadas à $1200 \mathrm{rpm}$. Os soros obtidos foram congelados à temperatura de $-20^{\circ} \mathrm{C}$ até $\mathrm{O}$ momento da realização da sua quantificação sérica, por meio do método de ensaio de imunofluorescência polarizada (IFP), realizada no aparelho AxYM SYSTEM $\mathrm{ABBOT}^{\circledR}$. As leituras foram realizadas no Laboratório de Análises Clínicas do Hospital Universitário da Faculdade de Medicina da Universidade de São Paulo. Os resultados das concentrações séricas de fenobarbital, nos diferentes horários de colheita, foram submetidos ao teste de múltiplas comparações de Dunn, seguido pelo Teste de Friedman ANOVA de medidas repetitivas, não paramétrico ${ }^{14}$. As diferenças foram consideradas significantes quando $\mathrm{p}<0,05$. Para estimar as meias-vidas de eliminação foi utilizada a seguinte fórmula:

$$
\mathrm{T}_{1 / 2}=\frac{0,693}{\beta}
$$

Onde: $\beta$ é a constante de velocidade de eliminação global e representa o valor negativo da inclinação da fase de eliminação do gráfico log das concentrações séricas em relação ao tempo. Como uma primeira aproximação, a meia-vida foi estimada, graficamente, a partir de uma representação semilogarítmica da concentração plasmática da droga, após sua administração (em escala logarítmica) pelo tempo (escala linear). ${ }^{15}$ As meias-vidas obtidas no presente trabalho, foram calculadas utilizando-se três a quatro 


\section{Resultados e Discussão}

Observou-se ampla variação nos valores de meia-vida: 13-131 horas e média $44 \pm 29,3$ horas (tabela 1), sendo que 27 dos 30 cães apresentaram tempo de meiavida inferior a 72 horas. A Tabela 2 apresenta as concentrações séricas de fenobarbital $(\mathrm{mg} / \mathrm{mL})$ no intervalo de 12 horas e a dosagem oral $(\mathrm{mg} / \mathrm{kg} / \mathrm{dia})$ nos 30 cães medicados com dose estável de fenobarbital por um período mínimo de 30 dias, com intervalo de 12 horas entre as administrações. A figura 1 ilustra a média de concentração sérica de fenobarbital $(\mathrm{mg} / \mathrm{mL})$ e erro padrão.

Ocorreu diferença significante entre as amostras colhidas entre duas e quatro horas quando comparadas às obtidas imediatamente antes e oito, 10 e 12 horas após a administração da droga. Também houve diferença significante entre as amostras colhidas seis horas após a administração do fenobarbital com aquelas coletadas imediatamente antes da dose matutina e 12 horas após a administração do fenobarbital.

Não foram observadas diferenças significantes entre as médias das concentrações séricas das amostras coletadas imediatamente antes, com as amostras coletadas oito, 10 e 12 horas após a administração de fenobarbital. Também não se observaram diferenças significantes entre as amostras coletadas duas, quatro e seis horas após a administração do fenobarbital, tampouco entre as amostras colhidas seis horas, com as amostras colhidas duas, quatro, oito e 10 horas após sua administração (Tabela 2 e Figura 1). Os 10 cães medicados concomitantemente com brometo de potássio apresentaram resultados semelhantes.

No que tange a variação da concentração sérica de fenobarbital, os resultados obtidos no presente experimento foram diferentes dos observados por Levitski e Trepanier, ${ }^{12}$ que não obtiveram variação entre as médias das concentrações séricas das amostras sangüíneas coletadas imediatamente antes, três e seis horas após a administração de fenobarbital. Isso pode ter ocorrido porque nesse trabalho os autores dividiram os animais em diferentes categorias terapêuticas, e consideraram a ocorrência de variação apenas nos animais que apresentavam variação de categoria. Mesmo assim, três de 33 animais apresentaram variação de categoria.

Estudos experimentais realizados em cães, utilizando-se múltiplas dosagens de fenobarbital, apresentaram reduzida variação nos valores de meia vida. Ravis et al. ${ }^{9}$ medicaram seis cães, durante cinco dias, com dose de $2 \mathrm{mg} / \mathrm{kg}$ a cada oito horas, obtendo valores de meia- vida de 37,3-74,6 horas. Esse trabalho foi inconclusivo em termos de variação farmacocinética devido ao tempo limitado de duração de tratamento, pois cinco dias é tempo insuficiente para atingir-se o estado de equilíbrio dinâmico. Ravis,Pedersoli e Wike ${ }^{15}$ compararam a meia- vida de eliminação, em dez cães, após uma única dosagem e após uso crônico (90 dias), observando uma redução significativa da mesma, sendo que no grupo que recebeu dose mais alta $(11 \mathrm{mg} / \mathrm{kg} /$ a cada 24 horas), o encurtamento da meia-vida foi mais acentuado em relação aos cães que receberam doses menores $(5 \mathrm{mg} / \mathrm{kg} / \mathrm{dia})$. As meias vidas variaram de $47 \pm 10,7$ horas para o grupo com dose mais baixa e $31,1 \pm 4,4$ horas para o grupo com dose mais elevada. No entanto, Levitski e Trepanier ${ }^{13}$ encontraram valores muito mais amplos de meia-vida: 14-304 horas. Obtiveram amostras sangüíneas imediatamente antes, três e seis horas após a administração de fenobarbital, em 33 cães epilépticos, medicados há, no mínimo, três semanas com a mesma dose via oral, com intervalo de 12 horas entre as medicações, com média de $65 \pm 61,8$ horas, inclusive sugerindo que monitoração fosse realizada de três a quatro semanas após cada novo ajuste de dose, pois valores elevados de meia-vida levariam a um aumento significante no tempo necessário para atingir-se o estado de equilíbrio dinâmico (anteriormente aceito de aproxi- 
madamente 15 dias).

Os valores de meia-vida obtidos no presente estudo foram bem mais amplos que os observados por Ravis ${ }^{10}$, Pedersoli e Wike15 e et al. ${ }^{16}$ Essa maior variação pode ter ocorrido devido a fatores intrínsecos dos animais (tais como idade, sexo, raça) e/ou pelo fato de ter-se utilizado um número maior de animais, além de maior variação na dose e no tempo de tratamento. Apesar de observar-se ampla variação nos valores de meia- vida, os valores obtidos não chegaram a ser tão extremos quanto os obtidos por Levitski e Trepanier ${ }^{13,}$ provavelmente porque esses valores de meiavida foram estimados com poucas amostras, apenas três valores de concentração sérica, justamente nas primeiras horas após a

Tabela 1 - Valores obtidos de meia- vida (horas), em cada um dos 30 cães medicados há, no mínimo, 30 dias com a mesma dose, com intervalo de 12 horas entre as administrações- São Paulo- 2002

\begin{tabular}{|c|c|}
\hline Animal & Meia-vida (horas) \\
\hline 1 & 67 \\
\hline 2 & 71 \\
\hline 3 & 46 \\
\hline 4 & 96 \\
\hline 5 & 51 \\
\hline 6 & 32 \\
\hline 7 & 24 \\
\hline 8 & 24 \\
\hline 9 & 129 \\
\hline 10 & 44 \\
\hline 11 & 33 \\
\hline 12 & 32 \\
\hline 13 & 19 \\
\hline 14 & 46 \\
\hline 15 & 24 \\
\hline 16 & 42 \\
\hline 17 & 26 \\
\hline 18 & 45 \\
\hline 19 & 22 \\
\hline 20 & 39 \\
\hline 21 & 58 \\
\hline 22 & 131 \\
\hline 23 & 21 \\
\hline 24 & 43 \\
\hline 25 & 13 \\
\hline 26 & 21 \\
\hline 27 & 30 \\
\hline 28 & 33 \\
\hline 29 & 23 \\
\hline 30 & 20 \\
\hline
\end{tabular}


Tabela 2-Concentrações séricas de fenobarbital ( $\mathrm{mg} / \mathrm{mL})$, imediatamente antes da sua administração matutina e 2, 4, 6, 8, 10 e 12 horas após a mesma e dose via oral (mg/kg/dia) em 30 cães medicados há, no mínimo, 30 dias com a mesma dose, com intervalo de 12 horas entre as administrações- São Paulo- 2002

\begin{tabular}{|c|c|c|c|c|c|c|c|}
\hline Dose & Oh & $2 \mathrm{~h}$ & $4 \mathrm{~h}$ & $6 h$ & $8 \mathrm{~h}$ & $10 \mathrm{~h}$ & $12 \mathrm{~h}$ \\
\hline - 8,0 & 28,0 & 33,4 & 31,7 & 30,6 & 31,8 & 29,7 & 30,1 \\
\hline 4,6 & 19,5 & 18,8 & 19,5 & 19,2 & 20,3 & 18,4 & 19,2 \\
\hline 7,2 & 27,9 & 33,3 & 31,6 & 30,4 & 29,9 & 29,2 & 27,9 \\
\hline 7,0 & 26,5 & 28,1 & 28,5 & 28,3 & 27,6 & 28,9 & 26,9 \\
\hline 5,4 & 19,7 & 23,7 & 22,2 & 22,5 & 20,3 & 20,1 & 20,7 \\
\hline - 4,0 & 14,5 & 15,2 & 15,6 & 14,7 & 14,3 & 14,6 & 15,2 \\
\hline - 7,5 & 18,8 & 23,7 & 24,3 & 23,1 & 21,4 & 21,6 & 19,4 \\
\hline - 2,2 & 12,5 & 12,2 & 13,2 & 12,2 & 11,5 & 10,8 & 10,4 \\
\hline 5,7 & 19,8 & 22,1 & 21,5 & 22,9 & 21,4 & 21,6 & 20,6 \\
\hline 4,2 & 9,9 & 12,8 & 12,1 & 13,1 & 11,7 & 12,8 & 11,8 \\
\hline 8,4 & 19,1 & 24,4 & 21,4 & 22,3 & 21,1 & 18,8 & 19,6 \\
\hline 4,0 & 18,5 & 21,8 & 21,3 & 21,5 & 18,9 & 20,1 & 17,9 \\
\hline 10,4 & 34,4 & 42,0 & 38,0 & 37,6 & 34,3 & 31,6 & 32,5 \\
\hline 7,8 & 17,9 & 24,5 & 23,4 & 21,9 & 20,2 & 20,5 & 20,0 \\
\hline - 4,4 & 19,8 & 22,4 & 23,5 & 22,2 & 20,9 & 21,3 & 18,6 \\
\hline 9,0 & 26,0 & 30,4 & 27,6 & 25,4 & 26,3 & 27,0 & 24,2 \\
\hline 7,6 & 14,0 & 20,3 & 23,0 & 18,9 & 17,9 & 17,0 & 16,9 \\
\hline 5,2 & 16,8 & 18,5 & 18,8 & 16,7 & 16,6 & 17,2 & 16,6 \\
\hline - 8,4 & 25,6 & 30,0 & 30,2 & 28,5 & 27,4 & 27,7 & 27,7 \\
\hline - 8,0 & 21,3 & 24,3 & 26,0 & 24,9 & 23,9 & 22,0 & 22,5 \\
\hline 6,6 & 26,5 & 28,7 & 26,3 & 26,9 & 26,6 & 24,3 & 25,1 \\
\hline - 8,6 & 28,1 & 33,1 & 30,7 & 30,6 & 30,1 & 30,6 & 29,5 \\
\hline 6,4 & 24,9 & 26,7 & 33,4 & 30,7 & 28,4 & 27,5 & 26,8 \\
\hline 8,0 & 33,2 & 40,3 & 38,2 & 34,2 & 33,9 & 31,0 & 33,4 \\
\hline 4,0 & 18,1 & 23,2 & 22,2 & 21,5 & 20,8 & 21,6 & 21,3 \\
\hline - 14,0 & 36,3 & 38,7 & 43,5 & 37,5 & 41,2 & 36,5 & 33,3 \\
\hline 8,6 & 20,2 & 26,0 & 26,6 & 24,6 & 24,7 & 21,7 & 20,8 \\
\hline - 5,7 & 17,8 & 22,8 & 20,0 & 20,9 & 19,4 & 18,3 & 17,7 \\
\hline 6,7 & 19,9 & 23,8 & 24,2 & 22,8 & 22,6 & 22,6 & 20,5 \\
\hline 6,9 & 19,7 & 23,8 & 21,3 & 20,2 & 18,9 & 19,3 & 18,0 \\
\hline 10,4 & 34,4 & 42,0 & 38,0 & 37,6 & 34,3 & 31,6 & 32,5 \\
\hline
\end{tabular}


Figura 1 - Média das concentrações séricas de fenobarbital $(\mathrm{mg} / \mathrm{ml})$ imediatamente antes da sua administração matutina e duas, quatro, seis, oito 10 e 12 horas após a mesma, com intervalo de 12 horas entre as administrações. os dados estão expostos em médias e erros padrões. Os grupos indicados por números são estatisticamente diferentes-São Paulo- 2002

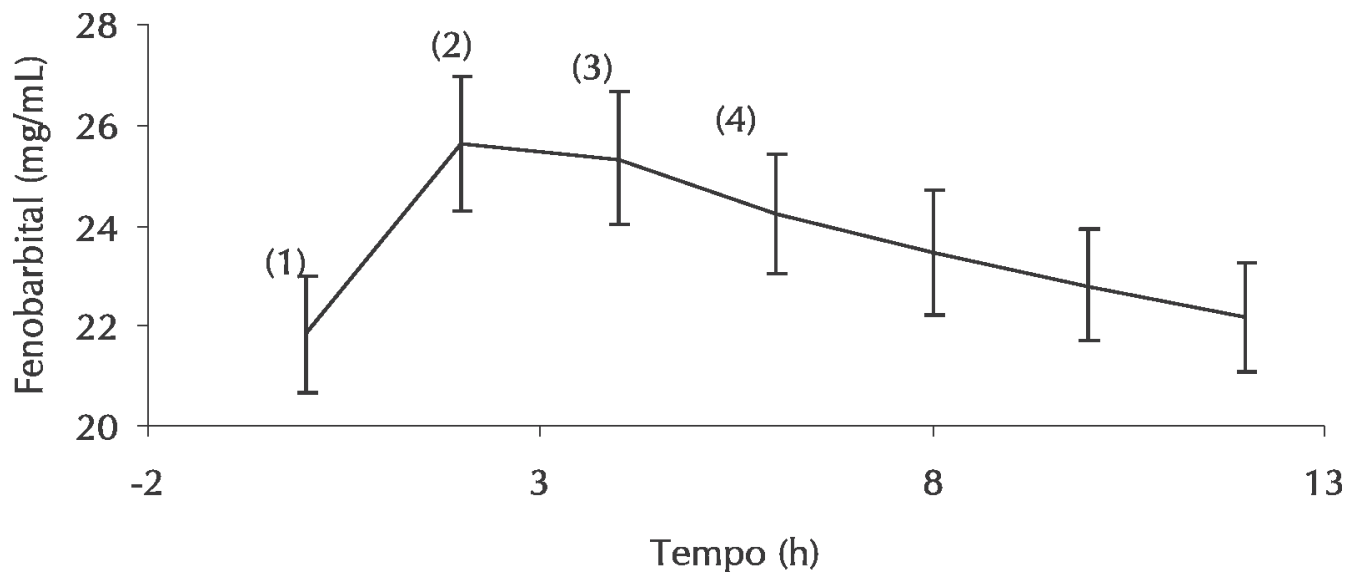

(1):Diferente significantemente das coletas às $2 h$, 4h e $6 \mathrm{~h}(\mathrm{p}<0,001$, Teste de múltiplas comparações de Dunn, seguido pelo Teste de Friedman); (2): Diferente significantemente das coletas às $0 \mathrm{~h}, 8 \mathrm{~h}, 10 \mathrm{~h}$ e $12 \mathrm{~h}(\mathrm{p}<0,01$, Teste de múltiplas comparações de Dunn, seguido pelo Teste deFriedman); (3) : Diferente significantemente das coletas às $0 h, 8 \mathrm{~h}, 10 \mathrm{~h}$ e $12 \mathrm{~h}(\mathrm{p}<0,001$, Teste de múltiplas comparações de Dunn, seguido pelo Teste de Friedman);

(4): Diferente significantemente das coletas às 0 h e $12 \mathrm{~h}(\mathrm{p}<0,001$, Teste de múltiplas comparações de Dunn, seguido pelo Teste de Friedman)

administração do fenobarbital, podendo não ser representativas. Apesar da obtenção de valores de meia-vida variáveis, para a grande maioria dos animais do experimento $90 \%$ (27/30), a monitoração quinze dias após o início da terapia seria válida, mas aguardando quatro semanas, o equilíbrio dinâmico seria obtido por $100 \%$ dos cães.

\section{Conclusões}

$\mathrm{Na}$ análise dos resultados obtidos, por meio da metodologia utilizada no presente trabalho, fundamentam-se as seguintes conclusões:

a) devido à ampla variação na meiavida de eliminação (de 13-131 horas), recomenda-se que as colheitas, com propósito de monitoração, sejam realizadas quatro semanas após o início do tratamento ou de cada novo ajuste de dose;

b) a colheita de material para a monitoração, com a finalidade de ajustar a dose, pode ser realizada em qualquer horário entre oito e 12 horas, após a administração do fenobarbital, ou imediatamente antes da mesma. No caso de suspeita de intoxicação, deve-se optar por duas coletas, sendo a primeira, entre oito e 12 horas após a sua administração matutina, ou imediatamente antes da administração noturna, enquanto uma segunda amostra deve ser coletada duas a quatro horas após sua administração.

Agradecimentos: ao CNPq, ao Prof. Dr. Carlos Adalberto de Camargo Sannazzaro do Hospital Universitário da USP e ao Prof. Dr. Marcelo Nicolás Muscará do Departamento de Farmacologia do Instituto de Ciências Biomédicas da USP e ao Médico Veterinário João Pedro de Andrade Neto.

\section{Study of the variation in the serum concentrations of phenobarbital in dogs exposured to a long term treatment}

\section{Abstract}

In order to evaluate daily changes of concentration of phenobarbital during the interval of 12 hours of its administration, serum phenobarbital concentration were measured each two hours in 30
Key-words:

Phenobarbital.

Serum concentration. Monitoring serum.

Dog.

Epilepsy. 
dogs submitted to the referred drug therapy for at least one month. All serum phenobarbital drug concentration were determined by use of a fluorecence polarization immunoassay. The values of half-lives obtained varied from 13 to 131 hours, most dogs reached steaty state serum concentrations by 15 days, and all dogs after four weeks. Therefore, clinicians should monitor serum phenobarbital concentrations four weeks after initiating treatment or after a change in dosage. There was significant difference among the averages of the samples two and four hours (peak) with the ones samples colected immediately before, and eight, 10 and 12 hours after its administration. In order to monitore serum phenobarbital concentrarions, its is suggest that blood collection is measured just before the dose or at any time between eight and 12 hours after its administration. If a concern arises regarding toxicity, a second sample should be colleted between two and four hours after phenobarbital administration.

\section{Referências}

1 FARNBACH, G. C. Serum concentrations and afficacy of phenytoin, Phenobarbital, and primidone in canine epilepsy, Journal of the American Veterinary Medical Association, v. 184, n. 9, p. 1117-1120, 1984.

2 FARNBACH, G. C. Seizures in the dog. Part II. Control. The Compendium on Continuing Education Article 5, v. 7, n. 6, p. 505-510, 1985.

3 PODELL, M. Seizures in dogs. Veterinary Clinics of North America: Small Animal Practice, v. 26, n. 4, p. 779-809, 1996.

4 FORRESTER, S. D.; BOOTHE, D. M.; TROY, G. C. Current concepts in the management of canine epilepsy. The Compendium on Continuing Education Article 3, v. 11, n. 7, p. 811-820, 1989.

5 PODELL, M. Antiepileptic drug therapy. Clinical Techniques in Small Animal Practice, v. 13, n. 3, p. 185-192, 1998.

6 BOOTHE, D. M. Anticonvulsant therapy in small animals. Veterinary Clinics of North America: Small Animal Practice, v. 28, n. 2, p. 411-448, 1998.

7 PARENT, J. M. Clinical management of canine seizures. Veterinary Clinics of North America: Small Animal Practice, v. 18, n. 4, p. 947-965, 1988.

8 SILVA, P. Meia-vida das drogas. In: Farmacologia, 2. ed. Rio de Janeiro: Guanabara Koogan, 1985. p. 42-45.51.

9 SILVA,P. Concentração plasmática das drogas. In: Farmacologia. 2.ed. Rio de Janeiro: Guanabara Koogan,1985. p.46-51

10 RAVIS, W. R.et al. Pharmacokinetics of phenobarbital in dogs after multiple oral administration. Amerian Journal Veterinary Research, v. 45, n. 7, p. 1283-1286, 1984.

11 AL-TAHAN, F.; FREY, H. H. Absorption kinetics and bioavailability of phenobarbital after oral administration to dogs. Journal of Veterinary Pharmacology and Therapeutics, v. 8, n. 1, p. 205-207, 1985.

12 FREY, H. H.; LOSCHER, W. Pharmacokinetics of anti- epileptic drugs in the dog: a review. Journal of Veterinary Pharmacology and Therapeutics, v. 8, n. 3, p. 219-233, 1985.

13 LEViTSKI, R. E.; TREPANIER, L. A. Effect of timing of blood collection on serum phenobarbital concentrations in dogs with epilepsy, Journal of the American Veterinary Medical Associaton, v. 217, n. 2, p. 200204, 2000.

14 JERROLD, H. Z. Biostatistical analysis. 3. ed. Prentice Hall, 1996

15 BAGGOT, J. D. Distribuição, metabolismo e eliminação das drogas no organismo. In: BOOTH, N. H.; McDONALD, L. E. Farmacologia e terapêutica em veterinária. 6. ed. Rio de Janeiro: Guanabara Koogan, 1992. p. 38-39.

16 RAVIS, W. R.; PEDERSOLI, W. M.; WIKE, J. S. Pharmacokinetics of phenobarbital in dogs given multiple doses. American Journal Veterinary Research, v. 50, n. 8 , p. $1343-1347,1989$

17 BOOTHE, D. M.; SIMPSON, G.; FOSTER, T. Effects of serum separation tubes on serum benzodiazepine and phenobarbital concentrations in clinically normal and epileptic dogs. American Journal Veterinary Research, v. 57, n. 9, p. 1299-1303, 1996.

18 FARNBACH, G. C. Efficacy of primidone in dos with seizures unresponsive to phenobarbital. Journal of the American Veterinary Medical Association, $v$. 185 , n. 8 , p. $867-868,1984$. 